\title{
Induction of sucrose synthase in the phloem of phytoplasma infected maize
}

\author{
J. BRZIN, N. PETROVIČ, M. RAVNIKAR and M. KOVAČ** \\ Department of Plant Biotechnology and Systems Biology, National Institute of Biology, \\ Večna pot 111, SI-1000 Ljubljana, Slovenia
}

\begin{abstract}
In this study, we have analyzed the expression of the low oxygen inducible sucrose synthase isozyme SH1 (SUS-SH1) in the phloem of maize (Zea mays L.) infected with maize bushy stunt phytoplasma. Immunolocalization and Western blot analysis revealed several fold induction of SUS-SH1 in companion cells of phytoplasma inhabited phloem of leaf sheaths and stems. The results imply higher rates of sucrose metabolism and intensified hypoxia in the phloem.
\end{abstract}

Additional key words: companion cell, fructose, hypoxia, immunofluorescence, maize bushy stunt, Western blot, Zea mays.

The phloem of vascular plants is a unique cellular complex of enucleate sieve tubes intimately connected with metabolically hyperactive companion cells. The phloem is conceivably the largest and the most intricate cell continuum and it may not come as a surprise that it hosts the smallest and the simplest cells - phytoplasmas. This uncultivable, wall-less bacteria of the class Mollicutes inhabit the sieve tubes and cruise between plants by specific phloem feeding insect vectors and with the help of humans, i.e. by vegetative propagation and global transportation. Phytoplasma cause several hundred incurable plant diseases of considerable economic significance (Seemueller et al. 2002). The reduced translocation by the phloem was revealed by the pioneering studies on phytoplasma diseases (Braun and Sinclair 1978) however, its cause remains a black box.

The four sequenced phytoplasma genomes contain the minimum sets of metabolic pathways identified in an organism to date and no known pathogenesis genes (Oshima et al. 2002, Bai et al. 2006, Kube et al. 2008, Tran-Nguyen et al. 2008). Recently, unique phytoplasma proteins that target plant cell nuclei (Bai et al. 2009) and influence plant development (Hoshi et al. 2009) have been reported. Nevertheless, interference with the host sugar metabolism could be at the core of phytoplasma pathogenicity because the phloem transport is highly sensitive to the changes in sugar metabolism and the associate energy production (Van Bel 2003). The low yield of phytoplasma energy production limited to substrate level phosphorylation implies that they compete substantially with the phloem cells for the primary cell fuel, i.e. hexoses and, possibly, glycolytic intermediates. The competition for hexoses has been implicated in phytoplasma pathogenesis (Oshima et al. 2007). In order to support the energy demanding transport processes that maintain the sucrose gradient within the phloem, some of the transported sucrose is metabolized, the first step being cleavage by sucrose synthase (SUS) into fructose and UDP-glucose (Geigenberger et al. 1993). Operation of the SUS pathway in the phloem is consistent with the low oxygen concentrations within the phloem that limit phloem energy metabolism and sucrose transport (Van Dongen et al. 2003). SUS genes are typically upregulated by low oxygen concentrations (Geigenberger 2003).

Received 11 December 2009, accepted 21 June 2010.

Abbreviations: MBSP - maize bushy stunt phytoplasma; PVP - polyvinylpyrrolidone; SUS-SH1 - sucrose synthase isozyme SH1; SUS1- sucrose synthase isozyme 1

Acknowledgments: We are grateful to William Styer (Ohio State University, USA) for providing Dalbulus maidis and MBSP, Dr. Paolo Ermacora (University of Udine, Italy) for MBSP antibodies, Dr. Prem S. Chourey (University of Florida, USA) for maize seeds and antibodies, Dr. Marina Dermastia for critical reading (National Institute of Biology, Slovenia), Dr. Aleš Kladnik (University of Ljubljana, Slovenia) for valuable discussion and Dr. Roger Pain (Institute Jožef Stefan, Slovenia) for lecturing the manuscript. The work was funded by the Slovenian Research Agency.

* Corresponding author, fax: (+386) 12573847, e-mail: maja.kovac@nib.si 


\section{J. BRZIN et al.}

Here we report analysis of sucrose synthase isozyme SUS-SH1 protein expression in maize (Zea mays L.) infected with maize bushy stunt phytoplasma (MBSP, 16SrI-B). In maize, contrary to sugar induced isozyme SUS1 involved in sink sugar unloading and starch or cellulose biosynthesis, SUS-SH1 is typically induced by low oxygen and seems to primarily support the energy metabolism in low oxygen environment (Springer et al. 1986, Zeng et al. 1998, Subbaiah and Sachs 2001). The reporter gene after sus-shl promoter was specifically expressed in the phloem of potato (Graham et al. 1997) and it was induced by hypoxia in tobacco plants (Yang and Russel 1990).

The object of this study was to look at the crucial enzyme of phloem sugar metabolism and a marker of hypoxia in a phytoplasma infected plant. For this reason SUS-SH1 and phytoplasma were detected by immunolocalization, while the level of SUS-SH1 protein in different phloem rich tissues was analyzed by Western blot.

To obtain infected plants 10-d-old seedlings of inbred maize (Zea mays L.), cv. Mexican black sweet, line W22, were exposed for $3 \mathrm{~d}$ to a population of vector (Dalbulus maidis DeLong and Wolcott) acquisited with maize bushy stunt phytoplasma (MBSP; ribosomal subgroup 16SrI-B; originating from Poza Rico, Mexico). Plants were grown in two independent experiments in a quarantine greenhouse.

For Western blot analysis five healthy and five infected plants were sampled 10 weeks after infection. From the six uppermost internodes, samples of leaf blades $(n=13)$, midribs $(n=5)$, leaf sheaths $(n=12)$ and stems $(n=10)$, along with axial roots $(n=7)$ previously washed in water, were collected in pairs from healthy and infected plants and immediately frozen in liquid nitrogen. The soluble and membrane proteins were extracted according to modified method of Subbaiah and Sachs (2001) and the protein content was determined by $R C D C$ protein assay (Bio-Rad, Hercules, USA). Samples of $10 \mu \mathrm{g}$ of protein were separated by polyacrylamide gel electrophoresis (3\% stacking, $7.5 \%$ running gel) and electro blotted on PVP membranes. The membranes were blocked and probed with monoclonal anti-SUS-SH1 antibodies (1:20000; provided by Dr. Prem S. Chourey, Department of Plant Pathology, University of Florida, Gainesville, FL, USA), followed by anti-mouse antibodies conjugated with alkaline phosphatase (1:8000; Sigma, Taufkirchen, Germany). After the signal developed, (AP substrate, Bio-Rad) the membranes were dried and scanned. The band absorption was determined and the background subtracted by Gel-Pro analyzer 4.0 software (Media Cybernetics, Bethesda, USA). To standardize the band intensities on individual blots, relative band absorption was calculated by normalizing the band absorption of each sample to that of a Western blot control loaded in aliquots on each gel.

For microscopic analysis, blocks of tissue were fixed (for $1 \mathrm{~h}$ at $4{ }^{\circ} \mathrm{C}$ in $4 \%$ paraformaldehyde in phosphate buffered saline; PBS) and hand cut with a razor blade. For immunofluorescence (IF) microscopy, sections were double labelled with rabbit anti-SUS-SH1 serum (Echt and Chourey 1985) and mouse anti-MBSP monoclonal antibodies (Chen and Jiang 1988) followed by goat antirabbit Alexa fluor 546 and donkey anti-mouse Alexa fluor 488 conjugated secondary antibodies (Molecular Probes, Eugene, Oregon, USA). Red-green-blue (RGB) images were collected with a fluorescence microscope (Nikon Eclipse E800, Tokyo, Japan) equipped with a colour CCD camera, under ultraviolet (UV), blue and green excitation using appropriate filter sets. The blue emission from the image taken with UV excitation, corresponding to the background autofluorescence and the emission colour of each fluorochrome, i.e. green and red, from the images taken at blue and green excitation, respectively, were extracted using Lucia $G$ software (Laboratory Imaging, Prague, Czech Republic). The

Table 1. Total proteins and SUS-SH1 protein in soluble and membrane fractions of tissues of healthy and infected plants. Mean \pm SE. The differences between the samples from healthy and infected plants were evaluated by Student $t$-test $(*-P<0.05 ; * *-P<0.01$; $* * *-P<0.001)$.

\begin{tabular}{lllll}
\hline Tissue & Fraction & $\begin{array}{l}\text { Total proteins }\left[\mathrm{mg} \mathrm{g}^{-1}(\mathrm{f} . \mathrm{m} .)\right] \\
\text { infected }\end{array}$ & $\begin{array}{c}\text { SUS-SH1 protein [arbitrary units] } \\
\text { healthy }\end{array}$ \\
\hline Leaf lamina & soluble & $4.55 \pm 0.27$ & $3.72 \pm 0.27 *$ & $0.02 \pm 0.01$ \\
& membrane & $0.68 \pm 0.06$ & $0.54 \pm 0.09$ & $0.06 \pm 0.02$ \\
Midrib & soluble & $0.91 \pm 0.13$ & $1.06 \pm 0.18$ & $0.22 \pm 0.07$ \\
& membrane & $0.05 \pm 0.01$ & $0.11 \pm 0.03 *$ & $0.18 \pm 0.09$ \\
Leaf sheath & soluble & $0.65 \pm 0.08$ & $1.04 \pm 0.10 * *$ & $0.19 \pm 0.08$ \\
& membrane & $0.07 \pm 0.01$ & $0.10 \pm 0.02$ & $0.30 \pm 0.11$ \\
Stem & soluble & $1.01 \pm 0.13$ & $1.35 \pm 0.19$ & $2.30 \pm 0.39$ \\
Roots & membrane & $0.11 \pm 0.03$ & $0.10 \pm 0.02$ & $2.17 \pm 0.35$ \\
& soluble & $0.23 \pm 0.03$ & $0.33 \pm 0.05$ & $1.82 \pm 0.38$ \\
& membrane & $0.02 \pm 0.00$ & $0.02 \pm 0.00$ & $1.02 \pm 0.32$ \\
\hline
\end{tabular}



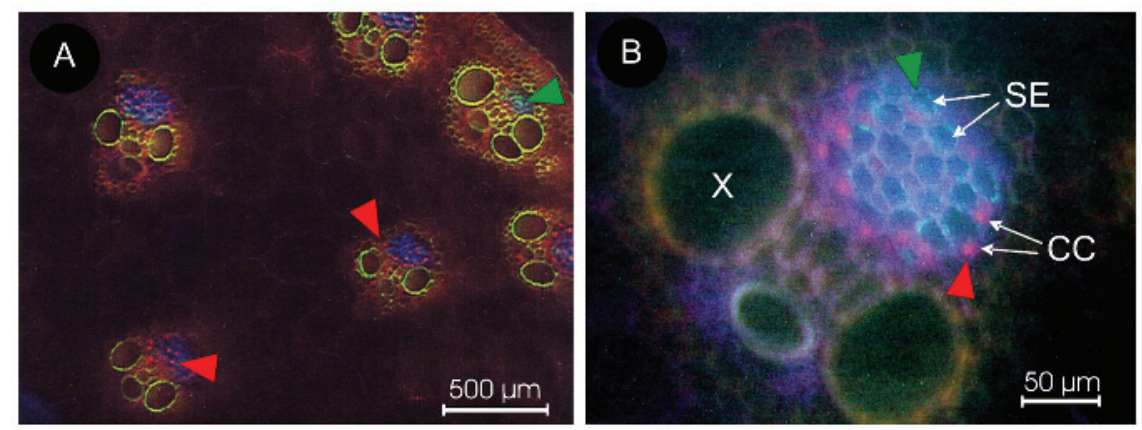

Fig. $1 A, B$. Immunolocalization of phytoplasma and SUS-SH1 in a cross section of major vascular bundles in stem. Phytoplasma (green fluorescence, arrowheads) are present in sieve elements (SE). SUS-SH1 (red fluorescence, arrowheads) is localized in companion cells (CC); X - xylem.

extracted colours were merged back into RGB images, in which green and red represent the specific signal of fluorochromes, while the background autofluorescence covers the rest of the spectrum.

Four weeks after infection, the first symptoms appeared on the leaves as irregular interveinal redness, and phytoplasma were observed by IF microscopy in the sieve tubes. At the time of sampling for biochemical analysis, plants were stunted with underdeveloped roots. Leaves had symptoms of sugar accumulation (Junqueira et al. 2004). The reduced level of proteins in leaf lamina (Table 1) could be attributed to repression of photosynthetic genes in sugar accumulating leaves (Paul and Pellny 2003).

SUS localized to companion cells of the phloem by Nolte and Koch (1993) has been in this study identified as isozyme SUS-SH1 (Fig. 1). Besides the companion cells throughout the plant, SUS-SH1 signal was only seldomly observed in xylem parenchyma cells of the major veins. By Western blot analysis, the highest levels of SUS-SH1 were found in stem and very low in leaf lamina in both healthy and infected plants (Table 1). While this in one sens reflects the different proportions of vascular tissue in samples, it appears that SUS-SH1 operates primarily in the transport phloem. Importantly, SUS-SH1 was induced several fold in leaf sheaths and stem of infected plants (Table 1), which is a strong indication of a higher level of sucrose metabolism and intensified hypoxia in the phloem. These results, the induction of SUS and alcohol dehydrogenase in phytoplasma infected grapevine (Hren et. al. 2009) along with the low ATP/ADP ratio and high reducing sugar concentrations in the phloem sap of phytoplasma infected apple trees (Kollar and Seemüller 1990), manifest that phytoplasma infection in diverse plants leads to sucrose mobilization, lack of oxygen and switch to the fermentative metabolism in the phloem.

Plants decrease their oxygen consumption in response to low oxygen concentrations to avoid internal anoxia (Zabalza et al. 2009). This adaptive response involves a rapid restriction of glycolytic flux and respiration, well before oxygen concentration becomes limiting for the respiration itself (Geigenberger 2003). However, in plant tissues with slow diffusion of oxygen, like tubers (Bologa et al. 2004) and the phloem (Zuther et al. 2004, Geigenberger et al. 2004), unregulated increase in sugar metabolism by genetic modification leads to a stimulation of respiration, resulting in a decrease in oxygen tension to almost zero, and a decrease in energy status. We propose that similarly, due to the near equlibrium reaction of SUS in the phloem and feed-back inhibition by fructose (Geigenberger et al. 1993), a simple competition for fructose in phytoplasma infested phloem stimulates sucrose breakdown and increases the rate of UDP-glucose

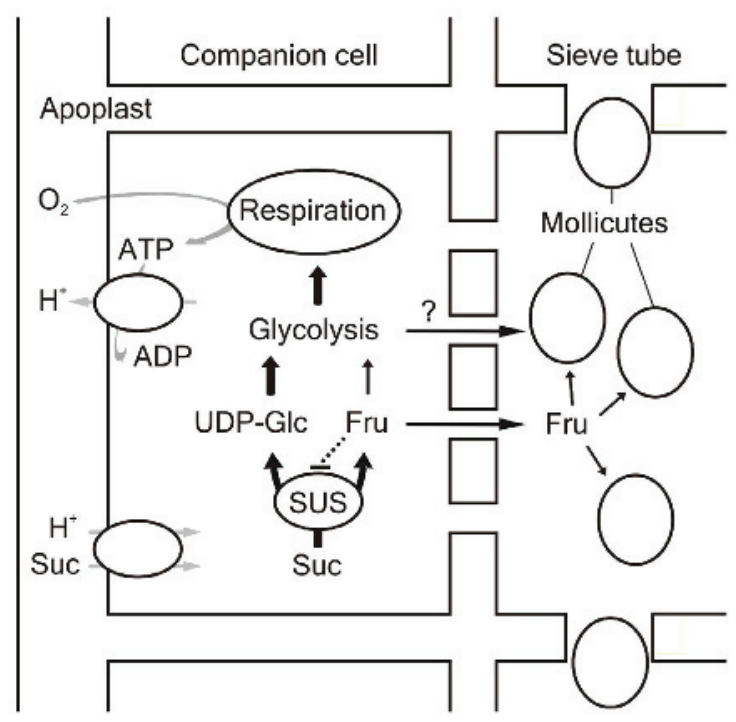

Fig. 2. The proposed model of Mollicutes pathogenesis. The competition for fructose stimulates sucrose breakdown because of alleviated feed-back inhibition of sucrose synthase (dashed line). More UDP-glucose enters glycolysis and respiration of the host cell (bold arrow). Oxygen supply by diffusion cannot keep up with the increased oxygen consumption in respiration, causing oxygen shortage in the phloem. Hypoxic metabolism cannot support the energetically demanding sucrose pumping that maintain high sucrose content within phloem (grey arrows). A possible competition for glycolytic intermediates is marked by ?. Fru - fructose, Suc - sucrose, SUS - sucrose synthase, UDP-Glc - UDP glucose. 
metabolism by host cells that leads to intensified hypoxia in the phloem (Fig. 2). The fact that fructose and not glucose utilization is crucial for pathogenicity of phytoplasma's relative, Spiroplasma citri (André et al. 2005), supports the proposed model as a common basis of pathogenesis in plant-pathogenic Mollicutes.

New experimental approaches for measuring oxygen in the phytoplasma inhabited phloem need to be employed to verify the model. Nevertheless, the low energy state of hypoxic phytoplasma inhabited phloem could explain the impaired phloem transport and its associated symptoms. The low energy state causes sucrose leaking from the transport phloem, which disrupts sucrose gradient, i.e., the driving force of phloem transport on the whole plant level (Wright and Oparka 1997, Ayre et al. 2003). An indication of sucrose leaking from the phytoplasma inhabited phloem are elevated protein contents in the tissues rich in transport phloem (Table 1), that could be due to sucrose induced protein synthesis (Geigenberger et al. 2000). A low oxygen environment reduces oxidative DNA damage, which

\section{References}

André, A., Maucourt, M., Moing, A., Rolin, D., Renaudin, J.: Sugar import and phytopathogenicity of Spiroplasma citri: glucose and fructose play distinct roles. - Mol. PlantMicrobe Interact. 18: 33-42, 2005.

Ayre, B.G., Keller, F., Turgeon, R.: Symplastic continuity between companion cells and the translocation stream: longdistance transport is controlled by retention and retrieval mechanisms in the phloem. - Plant Physiol. 131: 1518-1528, 2003.

Bai, X, Correa, V.R., Toruño, T.Y., Ammar, el-D., Kamoun, S., Hogenhout, S.A.: AY-WB phytoplasma secretes a protein that targets plant cell nuclei. - Mol. Plant-Microbe Interact. 22: 18-30, 2009.

Bai, X., Zhang, J., Ewing. A., Miller, S.A., Jancso, Radek, A., Shevchenko, D.V., Tsukerman, K., Walunas, T., Lapidus, A., Campbell, J.W., Hogenhout, S.A.: Living with genome instability: the adaptation of phytoplasmas to diverse environments of their insect and plant hosts. - J. Bacteriol. 188: 3682-3696, 2006

Bologa, K.L., Fernie, A.R., Leisse, A., Loureiro, M.E., Geigenberger, P.: A bypass of sucrose synthase leads to low internal oxygen and impaired metabolic performance in growing potato tubers. - Plant Physiol. 132: 2058-2072, 2004.

Braun, E.J., Sinclair, W.A.: Translocation in phloem necrosisdiseased american elm seedlings. - Phytopathology 68: 1733-1737, 1978.

Chen, T.A., Jiang, X.F.: Monoclonal antibodies against the maize bushy stunt agent. - Can. J. Microbiol. 34: 6-11, 1988.

Crawford, R.M.M., Braendle, R.: Oxygen deprivation stress in a changing environment. - J. exp. Bot. 47: 145-159, 1996.

Echt, C.S., Chourey, P.S.: A comparison of two sucrose synthase isozymes from normal and shrunken-1 maize. Plant Physiol. 79: 530-536, 1985. would be beneficial to phytoplasma that lack most of the DNA repair mechanisms (Oshima et al. 2002). Moreover, low oxygen suppresses the host cell defence response (Mittler et al. 1996). On the other hand, re-entry of oxygen into anoxic tissues leads to oxidative damage (Crawford and Braendle 1996, Kumutha et al. 2009) that could explain phloem necrosis in some phytoplasma diseases.

During the millions of years of co-evolution, Mollicutes have become excellent connoisseurs of the phloem and learned to manipulate the host metabolism. We propose that they, without any specific molecular interactions, i.e., by a simple competition for fructose, trick the host cell metabolism control into providing themselves with food and suitable low oxygen environment. The reduced function of hypoxic phytoplasma inhabited phloem could profoundly influence the plant development. The mechanism of pathogenesis proposed here could present a common basis of Mollicutes pathogenesis that has evolved early in the evolution.
Geigenberger, P.: Response of plant metabolism to too little oxygen. - Current Opin. Plant Biol. 6: 247-256, 2003.

Geigenberger, P., Fernie, A.R., Gibon, Y., Christ, M., Stitt, M.: Metabolic activity decreases as an adaptive response to low internal oxygen in growing potato tubers. - Biol. Chem. 381: 723-740, 2000.

Geigenberger, P., Langenberger, S., Wilke, I., Heineke, D., Heldt, H.W., Stitt, M.: Sucrose is metabolised by sucrose synthase and glycolysis within phloem complex of Ricinus communis L. seedlings. - Planta 190: 446-453, 1993.

Geigenberger, P., Regierer, B., Lytovchenko, A., Leisse, A., Schauer, N., Springer, F., Kossmann, J., Fernie, A.R.: Heterologous expression of a ketohexokinase in potato plants leads to inhibited rates of photosynthesis, severe growth retardation and abnormal leaf development. - Planta 218: 569-578, 2004.

Graham, M.W., Craig, S., Waterhouse, P.M.: Expression patterns of vascular-specific promoters RolC and Sh in transgenic potatoes and their use in engineering PLRVresistant plants. - Plant mol. Biol. 33: 729-735, 1997.

Hoshi, A., Oshima, K., Kakizawa, S., Ishii, Y., Ozeki, J., Hashimoto, M., Komatsu, K., Kagiwada, S., Yamaji, Y., Namba, S.: A unique virulence factor for proliferation and dwarfism in plants identified from a phytopathogenic bacterium. - Proc. nat. Acad. Sci. USA 106: 6416-6421, 2009.

Hren, M., Ravnikar, M., Brzin, J., Ermacora, P., Carraro, L., Bianco, P.A., Casati, P., Borgo, M., Angelini, E., Rotter, A. Gruden, K.: Induced expression of sucrose synthase and alcohol dehydrogenase I genes in phytoplasma-infected grapevine plants grown in the field. - Plant Pathol. 58: 170$180,2009$.

Junqueira, A., Bedendo, I., Pascholati, S.: Biochemical changes in corn plants infected by the maize bushy stunt phytoplasma. - Physiol. mol. Plant Pathol. 65: 181-185, 2004. 
Kollar, A., Seemüller, E.: Chemical composition of phloem exudate of mycoplasma-infected apple trees. - J. Phytopathol. 128: 99-111, 1990.

Kube, M., Schneider, B., Kuhl, H., Dandekar, T., Heitmann, K., Migdoll, A.M., Reinhardt, R., Seemüller, E.: The linear chromosome of the plant-pathogenic mycoplasma 'Candidatus Phytoplasma mali'. - BMC Genomics 9: 306, 2008.

Kumutha, D., Ezhilmathi, K., Sairam, R.K., Srivastava, G.C., Deshmukh, P.S., Meena, R.C.: Waterlogging induced oxidative stress and antioxidant activity in pigeonpea genotypes. - Biol. Plant. 53: 75-84, 2009.

Mittler, R., Shulaev, V., Seskar, M., Lam, E.: Inhibition of programmed cell death in tobacco plants during a pathogeninduced hypersensitive response at low oxygen pressure. Plant Cell 8: 1991-2001, 1996.

Nolte, K.D., Koch, K.E.: Companion-cell specific localisation of sucrose synthase in zones of phloem loading and unloading. - Plant Physiol. 101: 899-905, 1993.

Oshima, K., Miyata, S., Sawayanagi, T., Kakizawa, S., Nishigawa, H., Jung, H.-Y., Furuki, K., Yanazaki, M., Suzuki, S., Wei, W., Kubuyama, T., Ugaki, M., Namba, S.: Minimal set of metabolic pathways suggested from the genome of onion yellows phytoplasma. - J. gen. Plant Pathol. 68: 225-236, 2002.

Oshima, K., Kakizawa, S., Arashida, R., Ishii, Y., Hoshi, A., Hayashi, Y., Kagiwanda, S., Namba, S.: Presence of two glycolytic gene clusters in a severe pathogenic line of 'Candidatus Phytoplasma asteris'. - Mol. Plant Pathol. 8: 481-489, 2007.

Paul, M. J., Pellny, T.K.: Carbon metabolite feedback regulation of leaf photosynthesis and development. - J. exp. Bot. 54: 539-547, 2003.

Seemüller, E., Garnier, M., Schneider, B.: Mycoplasmas of plants and insects. - In: Razin, S., Herrmann, R. (ed.): Molecular Biology and Pathogenicity of Mycoplasmas. Pp. 91-115. Kluwer Academic Publishers/Plenum Press, New York 2002.

Springer, B., Werr, W., Starlinger, P., Bennett, D.C., Zokolica, M., Freeling, M.: The Shrunken gene on chromosome 9 of
Zea mays L. is expressed in various plant tissues and encodes an anaerobic protein. - Mol. gen. Genet. 205: 461$468,1986$.

Subbaiah, C.C., Sachs, M.M.: Altered patterns of sucrose synthase phosphorylation and localisation precede callose induction and root tip death in anoxic maize seedlings. Plant Physiol. 125: 585-594, 2001.

Tran-Nguyen, L.T., Kube, M., Schneider, B., Reinhardt, R., Gibb, K.S.: Comparative genome analysis of 'Candidatus Phytoplasma australiense، (subgroup tuf-Australia I; rp-A) and 'Ca. Phytoplasma asteris' strains OY-M and AY-WB. J. Bacteriol. 190: 3979-3991, 2008.

Van Bel, A.J.E.: The phloem, a miracle of ingenuity. - Plant Cell Environ. 26: 125-149, 2003.

Van Dongen, J.T., Schurr, U., Pfister, M., Geigenberger, P.: Phloem metabolism and function have to cope with low internal oxygen. - Plant Physiol. 131: 1529-1543, 2003.

Wright, K., Oparka, K.: Metabolic inhibitors induce symplastic movement of solutes from the transport phloem of Arabidopsis roots. - J. exp. Bot. 48: 1807-1814, 1997.

Yang, N.S., Russell, D.: Maize sucrose synthase-1 promoter directs phloem cell-specific expression of Gus gene in transgenic tobacco plants. - Proc. nat. Acad. Sci. USA 87: 4144-4148, 1990

Zabalza, A., Van Dongen, J.T, Froehlich, A., Oliver, S.N., Faix, B., Jagadis Gupta, K., Schmälzlin, E., Igal, M., Orcaray, L., Royuela, M., Geigenberger, P.: Regulation of respiration and fermentation to control the plant internal oxygen concentration. - Plant Physiol. 149: 1087-1098, 2009.

Zeng, Y., Wu, Y., Avigne, W.T., Koch, K.E.: Differential regulation of sugar-sensitive sucrose synthases by hypoxia and anoxia indicate complementary transcriptional and posttranscriptional responses. - Plant Physiol. 116: 1573 1583, 1998

Zuther, E., Kwart, M., Willmitzer, L., Heyer, A.G.: Expression of a yeast-derived invertase in companion cells results in long-distance transport of a trisaccharide in an apoplastic loader and influences sucrose transport. - Planta 218: 759$766,2004$. 